\title{
The Relationship between Hypomagnesemia and Pulmonary Function Tests in Patients with Chronic Asthma
}

\author{
Hatice Kılıc ${ }^{a}$ Asiye Kanbay ${ }^{b}$ Ayşegul Karalezlı ${ }^{a} \quad$ Elif Babaoglu ${ }^{a}$ \\ H. Canan Hasanoglu ${ }^{c}$ Ozcan Erel $^{d}$ Can Ates $^{e}$
}

${ }^{a}$ Department of Pulmonary Medicine, Ankara Atatürk Training and Research Hospital, Ankara, Turkey; ${ }^{\mathrm{b}}$ Department

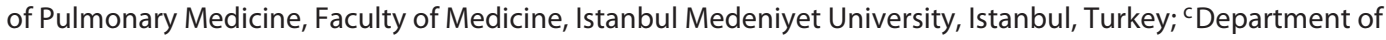
Pulmonary Medicine, Faculty of Medicine, Yıldırım Beyazit University, Ankara, Turkey; ${ }^{d}$ Department of Biochemistry, Faculty of Medicine, Yıldırım Beyazit University, Ankara, Turkey; ${ }^{e}$ Department of Biostatistics, Faculty of Medicine, Ankara University, Ankara, Turkey

\section{Significance of the Study}

- This study investigated the role of hypomagnesemia in asthmatic patients. We found that pulmonary function test parameters are decreased in patients with hypomagnesemia compared to patients with normomagnesemia. We suggest that hypomagnesemia could be important in the control of asthma.

\section{Keywords}

Asthma $\cdot$ Pulmonary function test $\cdot$ Hypomagnesemia . $\beta_{2}$-agonists $\cdot$ Hypophosphatemia $\cdot \mathrm{FEV}_{1}$

\begin{abstract}
Objective: To investigate the relationship between serum values of magnesium and the parameters of the pulmonary function tests (PFT) in patients with chronic asthma. Subjects and Methods: This study recruited 50 patients with chronic stable asthma and 40 healthy individuals as a control group. Data on age, sex, severity of asthma, PFT, and details of drug therapy were obtained from each group. Serum magnesium, potassium, phosphorus, calcium, and sodium levels were also measured. To evaluate differences between groups, the Student $t$ test or Mann-Whitney $U$ test was performed for continuous variables, and the $x^{2}$ test for categorical variables. Results: In the asthma group, $10 \%(n=9)$ of the
\end{abstract}

\begin{tabular}{ll}
\hline KARGER & $\begin{array}{l}\text { () 2018 The Author(s) } \\
\text { Published by S. Karger AG, Basel }\end{array}$ \\
E-Mail karger@karger.com & $\begin{array}{l}\text { This is an Open Access article licensed under the Creative Commons } \\
\text { Attribution-NonCommercial-4.0 International License (CC BY-NC) } \\
\text { (http://www.karger.com/Services/OpenAccessLicense), applicable to } \\
\text { the online version of the article only. Usage and distribution for com- } \\
\text { mercial purposes requires written permission. }\end{array}$
\end{tabular}

patients had hypomagnesemia and 5.5\% $(n=5)$ had hypophosphatemia. Patients with asthma were divided into two groups: the hypomagnesemic group $(n=9)$ and the normomagnesemic group $(n=41)$. Forced expiratory volume in $1 \mathrm{~s}$ $\left(\mathrm{FEV}_{1}\right), \mathrm{FEV}_{1} \%$, peak expiratory flow (PEF), and PEF\% were lower in the hypomagnesemic group than in the normomagnesemic group ( $p=0.02$ ). Multiple logistic regression analysis revealed a statistically significant association between hypomagnesemia and PFT in the hypomagnesemic asthmatic group. The correlations of age with $\mathrm{FEV}_{1}, \mathrm{FEV}_{1} \%$, PEF, and PEF\% were as follows: $p=0.00, r=0.29 ; p=0.00, r=$ $0.43 ; p=0.03, r=0.22 ; p=0.00, r=0.38$; and $p=0.03, r=0.22$, respectively. The correlation of serum magnesium levels with PFT (FEV $1, \mathrm{FEV}_{1} \%$, PEF, PEF\%) were as follows: $p=0.001$, $r=0.29 ; p=0.001, r=0.43 ; p=0.03, r=0.22$; and $p=0.001$, $r=0.38$, respectively. The other electrolytes were within the normal range in both groups. Conclusion: In this study, hypomagnesemia and hypophosphatemia were found to be
Hatice Kilıc

Ankara Atatürk Training and Research Hospital

Bilken, TR-06800 Ankara (Turkey)

E-Mail drhaticeb@yahoo.com 
the most common electrolyte abnormalities in patients with chronic stable asthma. FEV ${ }_{1}, \mathrm{FEV}_{1} \%, \mathrm{PEF}$, and PEF\% were significantly lower in asthmatic patients with hypomagnesemia compared to asthmatic patients with normomagnesemia.

(c) 2018 The Author(s)

Published by S. Karger AG, Basel

\section{Introduction}

Magnesium $\left(\mathrm{Mg}^{2+}\right)$ is an important intracellular and extracellular cation and a cofactor for many intracellular enzymatic reactions $[1,2] . \mathrm{Mg}^{2+}$ is involved in cellular homeostasis as an enzymatic cofactor, and in the release of acetylcholine and histamine from cholinergic nerve terminals and mast cells, respectively. Moreover, the effect of $\mathrm{Mg}^{2+}$ is proposed to be related to its ability to block the calcium ion influx to the smooth muscles of the respiratory system [3]. Finally, the role of $\mathrm{Mg}^{2+}$ as an anti-inflammatory agent has been identified in adults with asthma. This role is ubiquitous within the human body and has the clear potential to play an important role in asthma; however, the precise mechanism is unclear [1].

$\mathrm{Mg}^{2+}$ deficiency is associated with airway hyperreactivity, wheezing, and impaired lung function. Several studies have suggested that $\mathrm{Mg}^{2+}$ might play a beneficial role in the prevention and treatment of asthma through relaxation of the bronchial smooth muscles [4]. Beneficial effects of $\mathrm{Mg}^{2+}$ on lung function, airway reactivity, and wheezing were observed in two observational studies [5, 6]. However, other studies could not confirm these results [7]. Potential beneficial effects of dietary factors including $\mathrm{Mg}^{2+}$, copper, and zinc have been suggested and require further investigation [8].

This study aimed to investigate the relationship between serum $\mathrm{Mg}^{2+}$ values and the results of the pulmonary function test (PFT) in patients with chronic stable asthma, and to assess whether the severity of asthma has any effect on abnormal levels of electrolytes.

\section{Materials and Methods}

\section{Study Design}

Between June 2009 and June 2010, a clinical, case-controlled trial was conducted at Ankara Atatürk Training and Research Hospital (Ankara, Turkey). A total of 90 participants (26 males, 64 females) who were admitted to our department and satisfied the inclusion criteria were enrolled for the study. Fifty patients with the diagnosis of stable asthma (mild persistent asthma: 17 patients; moderate persistent asthma: 23 patients; severe asthma: 10 patients) and 40 healthy controls were included in the study. The
Table 1. Characteristics and outcomes of patients

\begin{tabular}{|c|c|c|c|}
\hline & $\begin{array}{l}\text { Asthma } \\
(n=50)\end{array}$ & $\begin{array}{l}\text { Control } \\
(n=40)\end{array}$ & $p$ \\
\hline Female/male, $n$ & $36 / 14$ & $28 / 12$ & 0.15 \\
\hline Age, years & $49.64 \pm 15.38$ & $46.50 \pm 13.99$ & 0.75 \\
\hline Magnesium, mg/dL & $2.16 \pm 0.43$ & $2.29 \pm 0.30$ & 0.04 \\
\hline Calcium, mg/dL & $9.24 \pm 0.48$ & $9.30 \pm 0.50$ & 0.64 \\
\hline Phosphorus, mg/dL & $3.48 \pm 0.60$ & $3.49 \pm 0.60$ & 0.90 \\
\hline Sodium, $\mathrm{mmol} / \mathrm{L}$ & $137.96 \pm 1.95$ & $140.37 \pm 2.19$ & 0.44 \\
\hline Potassium, mmol/L & $4.25 \pm 0.25$ & $4.3 \pm 0.32$ & 0.18 \\
\hline Hypomagnesemia, $n$ (\%) & $9(10)$ & 0 & \\
\hline $\mathrm{FEV}_{1}, \mathrm{~mL}$ & $2,251 \pm 830.90$ & $2,296 \pm 630.54$ & $>0.05$ \\
\hline $\mathrm{FEV}_{1} \%$ & $83.40 \pm 17.38$ & $86.62 \pm 16.52$ & $>0.05$ \\
\hline $\mathrm{PEF}, \mathrm{L} / \mathrm{h}$ & $5.58 \pm 2.12$ & $5.92 \pm 2.15$ & $>0.05$ \\
\hline PEF\% & $70.30 \pm 23.11$ & $75.24 \pm 21.15$ & $>0.05$ \\
\hline
\end{tabular}
flow.

$\mathrm{FEV}_{1}$, forced expiratory volume in $1 \mathrm{~s}$; PEF, peak expiratory

diagnosis of asthma was performed according to the Global Initiative for Asthma (GINA) 2010 guidelines [9].

The inclusion criteria were as follows: chronic stable asthma (defined as no history of exacerbation at the time of presentation or within the previous month), age $>18$ years, and nonsmokers. The exclusion criteria were medical conditions and disorders (such as chronic kidney disease, diabetes mellitus, cardiac disease, alcoholism, diarrhea, and pregnancy), and any treatment which might affect the absorption or excretion of $\mathrm{Mg}^{2+}$ including digoxin, diuretics, and calcium-containing medications.

All cases were evaluated with detailed history, general survey, and examination of the respiratory system. Asthmatic patients were assessed for severity based on GINA guidelines [9]. Asthmatic patients completed the PFT. These patients had mild persistent, moderate persistent, or severe asthma, and all required one or more medications for asthma. Medication use and symptom scores were also recorded. This study was approved by the Ethics Committee of the Ankara Atatürk Training and Research Hospital and written informed consent was obtained from all subjects. A venous blood sample was taken from all patients for measurement of levels of $\mathrm{Mg}^{2+}$, sodium $(\mathrm{Na})$, potassium $(\mathrm{K})$, phosphorus $(\mathrm{P})$, and calcium $(\mathrm{Ca})$. Normal values were as follows: $\mathrm{K}, 3.5-5.1 \mathrm{mg} /$ $\mathrm{dL} ; \mathrm{P}, 2.6-5.1 \mathrm{mg} / \mathrm{dL} ; \mathrm{Ca}, 8.6-10.0 \mathrm{mg} / \mathrm{dL} ; \mathrm{Na}, 136-145 \mathrm{mg} / \mathrm{L}$; and $\mathrm{Mg}^{2+}, 1.8-2.4 \mathrm{mg} / \mathrm{dL}$. Serum electrolyte levels were measured with the Advia 2400 Siemens autoanalyzer method in all participants.

In the hypomagnesemic group, 6 patients were on long-acting $\beta_{2}$-agonist (LABA)-inhaled corticosteroids (ICS) and montelukast, and 3 patients were on LABA-ICS $(n=9)$. In the normomagnesemic group, 13 patients were on ICS, 20 were on LABA-ICS, and 8 were on LABA-ICS and montelukast $(n=30)$.

\section{Pulmonary Function Test}

Forced expiratory volume in $1 \mathrm{~s}\left(\mathrm{FEV}_{1}\right)$, forced vital capacity, and peak expiratory flow (PEF) were measured using a spirometer (Spirolab, Italy). The best value of three maneuvers was selected as a percentage of the predicted value and as the absolute value. 
Table 2. Characteristics and outcomes of patients with hypomagnesemia and normomagnesemia

\begin{tabular}{lccc}
\hline & Hypomagnesemia & Normomagnesemia & $p$ \\
\hline $\mathrm{FEV}_{1}, \mathrm{~mL}$ & $1,746 \pm 692.71$ & $2,362.19 \pm 824.54$ & 0.02 \\
$\mathrm{FEV}_{1} \%$ & $70.44 \pm 17.54$ & $86.24 \pm 16.20$ & 0.02 \\
$\mathrm{PEF}, \mathrm{L} / \mathrm{h}$ & $4.79 \pm 2.12$ & $5.75 \pm 2.11$ & $\mathrm{NA}$ \\
$\mathrm{PEF} \%$ & $56.22 \pm 16.30$ & $73.39 \pm 23.39$ & 0.02 \\
Total immunoglobulin-E, mg/dL & $146.33 \pm 59.18$ & $182.38 \pm 173.39$ & $\mathrm{NA}$ \\
Eosinophilia, \% & $4.31 \pm 4.24$ & $3.24 \pm 2.29$ & $\mathrm{NA}$ \\
Mild asthmatic patients, $n(\%)$ & & $16(39)$ & $\mathrm{NA}$ \\
Moderate asthmatic patients, $n(\%)$ & $5(54.6)$ & $19(46.3)$ & NA \\
Severely asthmatic patients, $n(\%)$ & $4(44.4)$ & $6(14.6)$ & NA \\
\hline
\end{tabular}

NA, not available.

\section{Statistical Analysis}

The Kolmogorov-Smirnov and Shapiro-Wilk tests were used to test for normality of distribution of the data. Homogeneities of variances were tested by the Levene test. To evaluate differences between groups, the Student $t$ test or Mann-Whitney $\mathrm{U}$ test was performed for continuous variables, and the $\chi^{2}$ test for categorical variables. The degree of association between variables was calculated by point biserial, Spearman, Cramer's V, and phi correlation coefficients, where appropriate. Frequencies (percentages), mean \pm standard deviation (SD), and median (minimum-maximum) were calculated as descriptive statistics. Statistical analyses were performed by SPSS version 16.0 and $p<0.05$ was considered as statistically significant.

\section{Results}

The characteristics of the participants are summarized in Table 1. Demographic data and age and sex distribution in the asthmatic group did not differ from those in control subjects. The levels of $\mathrm{Mg}^{2+}$ in asthmatic patients were significantly lower than the levels in control subjects. Mean \pm SD of serum $\mathrm{Mg}^{2+}$ levels in asthmatic patients and control subjects were $2.16 \pm 0.43$ and $2.29 \pm$ 0.30 , respectively $(p=0.04)$. In the patient group, 17 (34\%) subjects had mild persistent asthma, 23 (46\%) had moderate persistent asthma, and 10 (20\%) had severe persistent asthma. We determined a statistically nonsignificant correlation between serum levels of $\mathrm{Mg}^{2+}$ and severity of asthma in the patient group ( $p=0.07, r=-0.25)$. We also determined a correlation between serum $\mathrm{Mg}^{2+}$ levels and PFT parameters in the patient group. However, this correlation was not significant. The correlations between serum levels of $\mathrm{Mg}^{2+}$ and $\mathrm{FEV}_{1}, \mathrm{FEV}_{1} \%, \mathrm{PEF}$, and $\mathrm{PEF} \%$ were not significant $(p=0.12, r=0.21 ; p=0.10, r=0.23$; $p=0.92, r=-0.01$; and $p=0.27, r=0.15$, respectively).

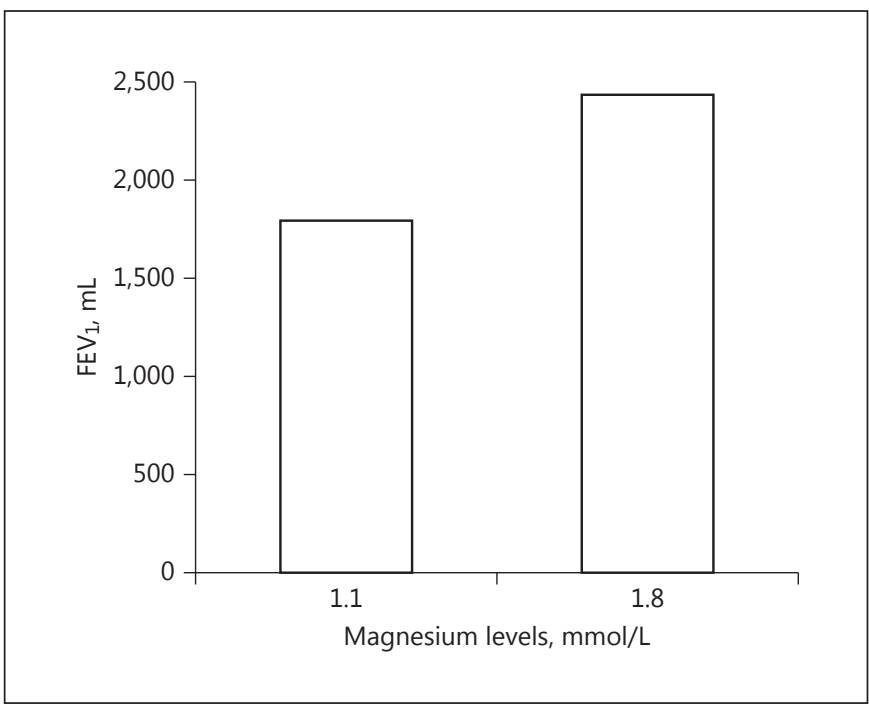

Fig. 1. Comparison between asthmatic patients with hypomagnesemia and asthmatic patients with normomagnesemia according to median $\mathrm{FEV}_{1}(p=0.02)$. $\mathrm{FEV}_{1}$, forced expiratory volume in $1 \mathrm{~s}$.

In this study, serum $\mathrm{Mg}^{2+}$ values in the range of 1.80 $2.40 \mathrm{mg} / \mathrm{dL}$ were considered normal, and any value below $1.8 \mathrm{mg} / \mathrm{dL}$ was defined as hypomagnesemia. We found that all subjects with hypomagnesemia were asthmatic. Using the cut-off value of $1.8 \mathrm{mg} / \mathrm{dL}$, a total of $9(10 \%)$ patients were found to be hypomagnesemic and their serum $\mathrm{Mg}^{2+}$ values were in the range of $1.10-1.80 \mathrm{mg} / \mathrm{dL}$ (Table 2).

$\mathrm{FEV}_{1}, \mathrm{FEV}_{1} \%, \mathrm{PEF}$, and $\mathrm{PEF} \%$ were significantly lower in asthmatic patients compared to asthmatic patients with normomagnesemia ( $p=0.02$ ) (Fig. 1 ). $\mathrm{FEV}_{1}, \mathrm{FEV}_{1} \%$, 
Table 3. Results of multivariate logistic regression

\begin{tabular}{|c|c|c|c|c|c|c|}
\hline \multirow[t]{2}{*}{ Variables } & \multirow[t]{2}{*}{ B } & \multirow[t]{2}{*}{ SE } & \multirow{2}{*}{$\begin{array}{l}\operatorname{Exp}(B) \\
\text { OR }\end{array}$} & \multicolumn{2}{|c|}{$95 \%$ CI } & \multirow[t]{2}{*}{$p$} \\
\hline & & & & lower & upper & \\
\hline $\mathrm{Mg}^{2+}$ & -0.869 & 0.589 & 0.419 & 0.132 & 1.330 & 0.140 \\
\hline $\mathrm{KCl}$ & -0.953 & 0.768 & 0.385 & 0.086 & 1.735 & 0.214 \\
\hline
\end{tabular}

$\mathrm{PEF}$, and PEF\% were correlated with serum $\mathrm{Mg}^{2+}$ levels in asthmatic patients with hypomagnesemia. All asthmatic patients with hypomagnesemia were assessed according to the severity of asthma: 5 (54.6\%) had moderate persistent asthma and $4(44.4 \%)$ had severe persistent asthma. In this study, 4 (40\%) of the severe asthmatic patients were hypomagnesemic.

Correlation analyses revealed a statistically significant association between hypomagnesemia and the parameters of PFT in the patient group with hypomagnesemia $\left(\mathrm{FEV}_{1}, p=0.001, r=0.29 ; \mathrm{FEV}_{1} \%, p=0.001, r=0.43\right.$; $\mathrm{PEF}$ $p=0.03, r=0.22$; and $\mathrm{PEF} \% p=0.00, r=0.38$ ). However, no significant association was determined between hypomagnesemia and severity of asthma, usage of $\beta_{2}$-agonists, sex, and usage of more than two medications $(p=0.08$, $r=0.31 ; p=0.92, r=0.01 ; p=0.27, r=0.11$; and $p=0.92$, $r=0.01$, respectively). Serum levels of $\mathrm{Na}, \mathrm{K}, \mathrm{Ca}$, and $\mathrm{P}$ were lower in the patient group compared to the control group, but the differences were not statistically significant (Table 1). In order to evaluate effective risk factors for the presence of asthma, variables such as age, $\mathrm{Mg}^{2+}, \mathrm{Ca}, \mathrm{KCl}$, and $\mathrm{P}$ were evaluated by univariate and then by multivariate logistic regression analysis. $\mathrm{As}_{\mathrm{Mg}^{2+}}$ and $\mathrm{KCl}$ showed $p<0.250$ at univariate analysis, multivariate logistic regression was run; the results are summarized in Table 3.

\section{Discussion}

In this study, there was a strong correlation between hypomagnesemia and the $\mathrm{FEV}_{1}, \mathrm{FEV}_{1} \%$, and $\mathrm{PEF} \%$ parameters of PFT in patients with chronic stable asthma. Hypomagnesemia was more prevalent in stable asthmatic patients than in nonasthmatic controls, and was related to the severity of asthma.

Hypomagnesemia has been suggested to be associated with increased incidence of wheezing, airway hyperreactivity, and impaired lung function [10]. International guidelines have recommended the use of intravenous
$\mathrm{Mg}^{2+}$ sulfate $\left(\mathrm{MgSO}_{4}\right)$ in the treatment of acute severe asthma. This is particularly important if $\mathrm{FEV}_{1}$ is between 25 and $30 \%$ of predicted value at presentation, or if the patient has demonstrated a poor response to short-acting $\beta_{2}$-agonists [11]. However, the effects of hypomagnesemia in chronic stable asthmatic adult patients are not well defined. Hypomagnesemia was found to be common in patients with chronic asthma, although the cause was unknown $[10,11]$. Asthmatic patients with low serum levels of $\mathrm{Mg}^{2+}$ were found to have more severe asthmatic symptoms and a higher incidence of asthma exacerbation and hospitalization than asthmatic patients with normal serum levels of $\mathrm{Mg}^{2+}[10,12]$. One possible explanation is that hypomagnesemia may induce bronchoconstriction via increased influx of Ca into the smooth muscle cells of the airway. An alternative explanation is that hypomagnesemia may induce bronchial hyperresponsiveness through increased histamine release from mast cells [12]. In this study, all hypomagnesemic patients were in the moderate or severe asthma groups. However, a statistically nonsignificant correlation was found between hypomagnesemia and severity of asthma.

In previous studies, the cause of hypomagnesemia in patients with acute asthma was related to the use of $\beta_{2^{-}}$ agonists either orally or intravenously, or by nebulization, rather than by inhalation [13-15]. In addition, oral or intravenous treatment can increase the costs $[16,17]$. Treatment with a $\beta_{2}$-agonist can reduce serum levels of $\mathrm{Mg}^{2+}$ via urinary loss or intracellular shift [18]. However, our results did not indicate a relationship between hypomagnesemia and the use of $\beta_{2}$-agonists in the chronic stable asthmatic patients.

In a previous study, Hill et al. [4] investigated the effects of dietary intake of $\mathrm{Mg}^{2+}$ on PFT in asthma. However, they did not find a significant improvement in $\mathrm{FEV}_{1}$ with short-term $\mathrm{Mg}^{2+}$ replacement. This is the first study to assess the effects of hypomagnesemia on PFT of asthmatic patients.

$\mathrm{Mg}^{2+}$ replacement treatment was not effective in chronic asthmatic patients in previous studies $[1,19]$. In an epidemiological study, reduced intake of $\mathrm{Mg}^{2+}$ was associated with hyperreactivity of the airways to methacholine. The authors concluded that dietary intake of $\mathrm{Mg}^{2+}$ was independently related to lung function, and low intake of $\mathrm{Mg}^{2+}$ may therefore be involved in the etiology of asthma [20,21]. In another multicenter trial, $\mathrm{MgSO}_{4}$ was demonstrated to improve pulmonary function in severe asthma [22]. A single dose of intravenous $\mathrm{MgSO}_{4}$ has been shown to be sufficient to treat patients with severe acute asthma attack [23]. The role of nebulized $\mathrm{MgSO}_{4}$ is 
less clear; however, international guidelines provide advice for the use of both nebulized and intravenous $\mathrm{MgSO}_{4}$. Despite these findings regarding acute asthma, the efficacy of long-term replacement therapy with oral $\mathrm{Mg}^{2+}$ remains to be clarified in chronic asthma $[1,24-26]$. As a result, clinical observations suggest heterogeneity in response, most likely related to treatment intensity, the medication used, and the severity of asthma [27, 28]. In one study, oral $\mathrm{Mg}^{2+}$ was supplemented for 16 weeks, yet no differences were found in PFT, symptoms, and use of bronchodilator. The patients in this study were diagnosed as mild or moderate asthmatic patients by physicians. Thus, further investigation and supplementation with $\mathrm{Mg}^{2+}$ in moderate and severe asthmatic patients is required.

The present study observed an additional electrolyte disturbance, known as hypophosphatemia, in asthmatic patients. Hypophosphatemia causes impaired respiratory muscle performance, and may worsen respiratory failure in severely ill acute asthmatic patients [12]. Previous studies showed that hypophosphatemia was observed in patients with acute asthma under treatment with nebulized $\beta_{2}$-agonist, intravenous aminophylline, and corticosteroids $[15,18]$. Hypophosphatemia may cause clinical deterioration in asthmatic patients due to respiratory muscle fatigue and myocardial depression.
The current study has several limitations. First, serum $\mathrm{Mg}^{2+}$ levels correlate poorly with total body storage levels, and serum $\mathrm{Mg}^{2+}$ may appear normal in spite of depletion. Second, the estimation of $\mathrm{Mg}^{2+}$ levels in red blood cells, white blood cells, or muscle cells would be more representative. However, this method is expensive, not readily available, and not clinically applicable. Therefore, serum levels of $\mathrm{Mg}^{2+}$ are often used to assess the change in the $\mathrm{Mg}^{2+}$ status, despite its limitation. The third limitation is the lack of a formal estimation of sample size in our study.

\section{Conclusion}

Hypomagnesemia and hypophosphatemia were found to be the most common electrolyte abnormalities in patients with chronic stable asthma in our study. $\mathrm{FEV}_{1}$, $\mathrm{FEV}_{1} \%, \mathrm{PEF}$, and $\mathrm{PEF} \%$ were significantly lower in asthmatic patients with hypomagnesemia than in asthmatic patients with normomagnesemia. The underlying cause remains unknown. Further studies are needed to confirm our findings and to clarify these etiologies.

\section{Disclosure Statement}

The authors declare no conflict of interest.

\section{References}

1 Rowe BH, Camargo CA: The role of magnesium sulfate in the acute and chronic management of asthma. Curr Opin Pulm Med 2008; 14:70-76.

2 Dominguez LJ, Barbagallo M, Di Lorenzo G, et al: Bronchial reactivity and intracellular magnesium: a possible for mechanism for the bonchodilating effects of magnesium in asthma. Clin Sci 1998;95:137-142.

3 Gourgoulianis KI, Chatziparasidis G, Chatziefthimiou A, et al: Magnesium as a relaxing factor of airway smooth muscles. J Aerosol Med 1996;3:1093-1097.

4 Hill J, Micklewright A, Lewis S, et al: Investigation of the effect of short-term change in dietary magnesium intake in asthma. Eur Respir J 1997;10:2225-2229.

5 Britton J, Pavord I, Richards K, et al: Dietary magnesium, lung function, wheezing, and airway hyper-reactivity in a random adult population sample. Lancet 1994;344:357362.

6 Soutar A, Seaton A, Brown K: Bronchial reactivity and dietary antioxidants. Thorax 1997; 52:166-170.
7 Butland BK, Fehily AM, Elwood PC: Diet, lung function and lung function decline in a cohort of 2,512 middle-aged men. Thorax 2000;55:102-108.

8 Fogarty A, Lewis SA, Serivener SI, et al: Oral magnesium and vitamin $\mathrm{C}$ supplements in asthma: a parallel group randomized placebocontrolled trial. Clin Exp Allergy 2003;33: 1355-1359.

9 Global Initiative for Asthma (GINA): Global strategy for asthma management and prevention. NHLBI/WHO Workshop Report. National Institute of Health. National Heart, Lung and Blood Institute. Revised 2010. www. ginasthma.com.

10 Alamoudi OS: Hypomagnesaemia in chronic, stable asthmatics: prevalence, correlation with severity and hospitalization. Eur Respir J 2000;16:427-431.

11 Neill AM, Martin IR, Weir R, et al: Community acquired pneumonia: aetiology and usefulness of severity criteria on admission. Tho$\operatorname{rax} 1996 ; 51: 1010-1016$.

12 Alamoudi OS: Electrolyte disturbances in patients with chronic, stable asthma. Chest 2001;120:431-436.
13 Gustafson T, Boman K, Rosenhall L, et al: Skeletal muscle magnesium and potassium in asthmatics treated with oral $\beta_{2}$-agonists. Eur Respir J 1996;9:237-240.

14 Bos WJ, Postma DS, Doormaal JV: Magnesiuric and calciuric effects of terbutaline in man. Clin Sci 1988;74:595-597.

15 Brady HR, Ryan F, Cunningham J, et al: Hypophosphatemia complicating bronchodilator therapy for acute severe asthma. Arch Intern Med 1989;149:2367-2368.

16 Khadadah M: The cost of asthma in Kuwait. Med Princ Pract 2013;22:87-91.

17 Abal AT, Ayed A, Nair PC, et al: Factors responsible for asthma and rhinitis among $\mathrm{Ku}$ waiti schoolchildren. Med Princ Pract 2010; 19:295-298.

18 Haffner CA, Kendall MJ: Metabolic effects of $\beta_{2}$-agonists. J Clin Pharm Ther 1992;17:155164.

19 Das SK, Haldar AK, Ghosh I, et al: Serum magnesium and stable asthma: is there a link? Lung India 2010;27:205-208.
Hypomagnesemia and Pulmonary

Function Test in Asthma
Med Princ Pract 2018;27:139-144

DOI: $10.1159 / 000487760$ 
20 Britton J, Pavord I, Richards K, et al: Dietary magnesium, lung function, wheezing, and airway hyperreactivity in a random adult population sample. Lancet 1994;344:357-362.

21 Swaminathan R: Magnesium metabolism and its disorders. Clin Biochem 2003;24:47-66.

22 Silverman RA, Osborn H, Runge J, et al: IV magnesium sulfate in the treatment of acute severe asthma: a multicenter randomized controlled trial. Chest 2002;122:489-497.
23 Rowe BH, Sevcik W, Villa-Roel C: Management of severe acute asthma in the emergency department. Curr Opin Crit Care 2011;17: 335-341.

24 Murata A, Ling PM: Asthma diagnosis and management. Emerg Med Clin North Am 2012;30:203-222.

25 Rosanoff A, Weaver CM, Rude RK: Suboptimal magnesium status in the United States: are the health consequences underestimated? Nutr Rev 2012;70:153-164.
26 Zandsteeg AM, Hirmann P, Pasma HR, et al: Effect of $\mathrm{MgSO}_{4}$ on $\mathrm{FEV}_{1}$ in stable severe asthma patients with chronic airflow limitation. Magnes Res 2009;22:256-261.

27 Heaney LG, McGarvey PA: Personalised medicine for asthma and chronic obstructive pulmonary disease. Respiration 2017;93:153-161.

28 Juliane SH, Duc-Dung N, Robert L, et al: Pharmacological therapy of bronchial asthma: the role of biologicals. Int Arch Allergy Immunol 2015;168:241-252. 